\title{
Technetium Chemistry in HLW: Role of Organic Complexants
}

\section{Progress Report}

Principal Investigator:

Co-Investigators:

David L. Blanchard, Jr.

Pacific Northwest National Laboratory

PO Box 999, P7-25

Richland WA 99352

509/372-2248 phone

509/372-3861 fax

dl.blanchard@pnl.gov

Herman M. Cho

Pacific Northwest National Laboratory

PO Box 999, K8-98

Richland WA 99352

509/376-2685 phone

509/376-2303 fax

hm.cho@pnl.gov

Yuanxian Xia

Pacific Northwest National Laboratory

PO Box 999, P7-50

Richland WA 99352

509/373-5767 phone

509/372-1632 fax

yuanxian.xia@pnl.gov

Nancy J. Hess

Pacific Northwest National Laboratory

PO Box 999, P7-50

Richland WA 99352

509/376-9808 phone

509/372-1632 fax

nancy.hess@pnl.gov

James A. Campbell

Pacific Northwest National Laboratory

PO Box 999, P8-08

Richland WA 99352

509/376-0899 phone

509/376-2329 fax

james.campbell@pnl.gov

Dhanpat Rai

Pacific Northwest National Laboratory

PO Box 999, P7-50

Richland WA 99352

509/373-5988 phone

509/372-1632 fax

dhan.rai@pnl.gov

Steven D. Conradson

Los Alamos National Laboratory

MST-8, MS G755

Los Alamos NM 87545

505/667-9584 phone

505/667-8021 fax

conradson@lanl.gov 


\section{Research Objective}

Tc contamination is found within the DOE complex at those sites whose mission involved extraction of plutonium from irradiated uranium fuel or isotopic enrichment of uranium. At the Hanford Site, chemical separations and extraction processes generated large amounts of high level and transuranic wastes that are currently stored in underground tanks. Technetium is thought to have followed $U$ in bismuth phosphate, REDOX and PUREX extraction campaigns and the $\mathrm{Cs}$ and $\mathrm{Sr}$ isotope recovery efforts. The waste from these extraction processes is currently stored in underground High Level Waste (HLW) tanks. However, the chemistry of the HLW in any given tank is greatly complicated by repeated efforts to reduce volume and recover isotopes. These processes ultimately resulted in mixing of waste streams from different processes. As a result, the chemistry and the fate of Tc in HLW tanks are not well understood. This lack of understanding has been made evident in the failed efforts to leach Tc from sludge and to remove Tc from supernatants prior to immobilization. Although recent interest in Tc chemistry has shifted from pretreatment chemistry to waste residuals, both needs are served by a fundamental understanding of Tc chemistry.

The fate of Tc in the insoluble salts that constitute tank residuals is of paramount importance due to the long half-life and environmental mobility of Tc. Knowledge gaps include determination of the Tc oxidation state, the stability of reduced Tc solution species, and interactions with possible organic complexants in HLW. The objective of this renewal proposal is to continue to pursue fundamental understanding of Tc solution chemistry that provides the basis to make knowledgeable decisions and predictions of Tc behavior during retrieval operations and in tank residuals.

\section{Research Progress and Implications}

Significant accomplishments were achieved during the first three years of funding. Several of these results have been published or submitted for journal publication.

- Much of the progress in understanding Tc chemistry we have attained in this research project can be attributed to ability to maintain rigorous reducing conditions over extended periods of time. In our solubility studies of Tc(IV) aqueous solution chemistry, a significant proportion, typically more than $85 \%$, of Tc in solution is present as Tc(IV). In contrast, previous studies were conducted in the presence of up to $100 \mathrm{X}$ excess of $\mathrm{Tc}(\mathrm{VII})$. The predominance of Tc(IV) solution species has been essential for spectroscopic investigations (UV-Vis and XAS), which greatly facilitate interpretation of our solubility studies. We have been able maintain the necessary reducing conditions for over 2 years in most systems.

- In our studies of the solubility of $\mathrm{TcO}_{2} \cdot n \mathrm{H}_{2} \mathrm{O}(\mathrm{am})$ to $3 \mathrm{M} \mathrm{NaOH}$, we have collected spectrophotometric data for the $\mathrm{TcO}(\mathrm{OH})_{3}{ }^{-}$and $\mathrm{TcO}(\mathrm{OH})_{4}{ }^{2-}$ species. In the absence of complexing ligands, weak amphoteric behavior of Tc(IV) to $\mathrm{pH} 12$ has been observed in the earlier studies and the formation of the $\mathrm{TcO}(\mathrm{OH})_{3}{ }^{-}$hydrolysis species has been proposed. To our knowledge, there has been no previous spectroscopic confirmation of the existence of these species.

- Stability of Tc(V)-carbonate complex in near neutral aqueous solution. We observe an increase in Tc solution concentrations of nearly 3 orders of magnitude in the presence of bicarbonate at

near neutral $\mathrm{pH}$. XANES analysis indicate that the oxidation state of this Tc-carbonate complex is $\mathrm{Tc}(\mathrm{V})$, a result that is supported by our spectrophometric measurements. The stability of 
highly soluble, reduced Tc-carbonate complex has important implications to the mobility of Tc in the environment.

- Most carboxylate ligands have limited stability above pH 10. We have observed a Tcgluconate complex that is stable beyond $5 \mathrm{M} \mathrm{NaOH}$. We believe that the enhanced stability is due the formation of multidentate bonding that involves not just the carboxylate groups but bonding through mid chain carbons along the carbon backbone. This result suggests the types of Tc-organic complexes that would be stable in HLW under alkaline conditions. The results on the Tc-gluconate complex will appear in Radiochimica Acta.

- We derived bond valence sum parameters for Tc-O bonds for oxidation states Tc(III) to Tc(VII) from X-ray diffraction data for crystalline Tc compounds. These results have been submitted to Inorganica Chimica Acta for publication.

\section{Planned Activities}

We have two experimental tasks outlined for the remainder of the EMSP three year research term: continued investigations of the structure of Tc precipitates under alkaline conditions and refinement of extraction conditions under extreme alkaline conditions. Our EXAFS initial investigations of the structure of $\mathrm{TcO}_{2} \cdot n \mathrm{H}_{2} \mathrm{O}(\mathrm{am})$ precipitates equilibrated under alkaline conditions suggest a subtle change in the radial distribution of distal Tc coordination shells from precipitates equilibrated at near neutral $\mathrm{pH}$ conditions. We plan to repeat the EXAFS experiments and conduct Raman microprobe investigation of the $\mathrm{TcO}_{2} \cdot n \mathrm{H}_{2} \mathrm{O}(\mathrm{am})$ equilibrated over wide range of hydroxide conditions. These investigations are planned for June through July 2004.

A second task is the refinement of solvent extraction conditions for solutions with hydroxide concentrations approaching $5 \mathrm{M} \mathrm{NaOH}$. Currently we use tetraphenylphosphonium chloride and chloroform as the organic phase which extracts anionicTc(VII), as $\mathrm{TcO}_{4}{ }^{-}$, into the organic phase and leaves the various $\mathrm{Tc}(\mathrm{IV})$ species in the aqueous phase under a wide range of $\mathrm{pH}$ conditions. However, at high hydroxide concentration we have observed the co-extraction of anionic Tc(IV) species, such as $\mathrm{TcO}(\mathrm{OH})_{3}{ }^{-}$, with $\mathrm{TcO}_{4}{ }^{-}$into the organic phase concomitant with a decrease in the distribution coefficient for $\mathrm{Tc}(\mathrm{VII})$. We have tried various strategies to exclusively extract $\mathrm{Tc}(\mathrm{VII})$ into the organic phase and increase the extraction efficency. These are mainly based on $\mathrm{pH}$ adjustment of the solution immediately preceding extraction. This approach necessitates the addition of highly concentrated acid that in turn further reduces the efficiency of the extraction of $\mathrm{Tc}(\mathrm{VII})$ in to the organic phase. We will investigate the use of ligands to prevent the extraction of Tc(IV) in to the organic phase. This work will continue through September 2004.

\section{Information Access}

Three journal articles and one technical report are in various stages of publication. In addition several presentations were made. These are listed below.

\section{Publications}

- "A thermodynamic model for the solubility of $\mathrm{TcO}_{2} \cdot \mathrm{xH}_{2} \mathrm{O}(\mathrm{am})$ in the aqueous Tc(IV)$\mathrm{Na}^{+}-\mathrm{Cl}^{-}-\mathrm{H}^{+}-\mathrm{OH}^{-}-\mathrm{H}_{2} \mathrm{O}$ system,” by N.J. Hess, Y. Xia, D. Rai, and S.D. Conradson. Journal of Solution Chemistry 33:199-227, 2004. 
- "Solubility of $\mathrm{TcO}_{2} \cdot x \mathrm{H}_{2} \mathrm{O}(\mathrm{am})$ in the presence of gluconate in aqueous solution," by N.J. Hess, Y. Xia, and A.R. Felmy, to be published in Radiochimica Acta.

- "Bond valence sums for Tc-O system from EXAFS data," by D.W. Wester and N.J. Hess, to be published in Inorganica Chimica Acta.

- "Hanford Tanks 241-AY-102 and 241-BX-101: Sludge Composition and Contaminant Release Data,” by Krupka et al. PNNL Technical Report, 2004.

Presentations

- "Solubility of $\mathrm{TcO}_{2} \cdot x \mathrm{H}_{2} \mathrm{O}(\mathrm{am})$ in the presence of gluconate in aqueous solution." Invited presentation at 2003 ACS Annual Meeting.

- “Technetium in HLW: An example of environmental science at PNNL.” Invited presentation in Merida, Mexico on May $26^{\text {th }} 2003$.

- "Technetium Chemistry in HLW: Role of Organic Complexants.” 2003 EMSP HLW Annual Workshop.

- “Technetium Chemistry in HLW: Role of Organic Complexants.” FY02 EMSP High Level Waste Workshop. 